\title{
BUILT ENVIRONMENT EDUCATION FOR YOUNG PEOPLE: ARCHITECTS AND URBAN PLANNERS USING CULTURAL HERITAGE AS A LEARNING RESOURCE
}

\author{
Marta Brković Dodig ${ }^{1}$, Sarah Klepp ${ }^{2}$, \& Angela Million ${ }^{3}$ \\ ${ }^{1}$ Architecture department, Faculty of Civil Engineering Management, Union University Nikola Tesla \\ (Serbia) \\ 1,2,3 Department Urban Design and Urban Development at the Institute of City and Regional Development, \\ Berlin University of Technology (Germany)
}

\begin{abstract}
Built environment education (BEE) uses tangible objects produced by humans, which constitute our built environment (BE) (i.e. buildings, bridges, monuments) to enrich learning for children. Monuments as facets of our material culture can be focal points of BEE. Cultural heritage has been used as a teaching resource in social studies, cultural geography, (art) history, and sustainable development. Although architects use monuments as BEE curricular resource; looking at the existing academic literature the topic is difficult to discern. Therefore, the article will critically reflect on Lost Traces projects - a Bavarian project for school children on cultural heritage. In 23 projects, through creative spatial interventions pupils had an opportunity to interact with historic relics, archaeological traces, abandoned buildings and constructions, rediscover and bring the 'lost places' in into the public awareness, thus transforming the relics into a common European future. In order to critically reflect on the practice of architects and urban planners as educators using monuments as a curricular resource, and a learning context, a further debate is needed regarding the understanding of cultural heritage and the educational processes around them as constantly evolving cultural constructs, the role of the educative planners, and the quality of design and planning tools as educational tools.
\end{abstract}

Keywords: Built environment education, cultural heritage, monuments, architects and urban planners, youth participation.

\section{Introduction}

Built environment education, also named architecture education, utilizes settlements, buildings and landmarks - as a subject, a context for learning and a curricular resource (Million and Heinrich, 2014). BEE incorporates educational activities related to cultural, arts, democratic, and environmental education using BE facets. BEE aims to support pupils` development of critical thinking in connection to spatial issues and high-quality BE, foster environmental stewardship, inform about participatory and democratic decision making processes, and ultimately help pupils understand "the interrelationships of humans with their environments in the past and present and in different parts of the world" (Graves, 1990: 2). Monuments as facets of our material culture can be focal points of BEE. Cultural heritage can enhance teaching of curricular subjects, can provide par excellence cross-curricular opportunities; transforming abstract concepts from textbooks "into tangible realities and intriguing stories about their everyday world" (Hunter, 1993: 2), while assisting pupils to appreciate local history and culture, and comprehend the importance of historic preservation. Educational projects involving monuments as a BEE curricular resource can be found internationally. Important contributions are coming from the English Heritage (Bradley et al., 2011) in the UK, 'Baukultur Aktiv' (active building culture) program from Switzerland (Fachwerk, n.d) 'Denkmal aktiv - Kulturerbe macht Schule' (active monument - cultural heritage makes school) program from Germany (DSD - Deutsche Stiftung Denkmalschutz, 2018), and Teaching with historic places (2016) from the USA. This paper seeks to discuss 'LOST TRACES' (LT) project as a mean to illustrate architects and urban planners' ways of working as educators, specifically focusing on using cultural heritage as BEE curricular resource, as well as to distil topics to initiate the future debate in this field. 


\section{Literature review}

Preliminary analysis revealed three groups of literature. The first group of studies consists of policy documents. On the European level the issues of teaching with BE, and monuments as a facet of BE, are addressed through Davos Declaration (2018) and Council of Europe (2005). 'Baukultur' or building culture in German, "embraces every human activity that changes the built environment", it embraces all designed and BE facets and their relation to natural environment; it includes planning and design processes, landscapes, cities, villages, infrastructure, buildings, monument and cultural heritage elements (Davos Declaration, 2018: 10). The Davos Declaration (2018) stressed that: "There is an urgent need for a holistic, culture-centered approach to the built environment and for a humanistic view of the way we collectively shape the places we live in and the legacy we leave behind." (p.10) In a similar fashion the Council of Europe (2005) through Faro Convention aimed to enhance participation in cultural heritage, stressing that cultural heritage should be understood as a legacy in a built form, resultant from the people-places interactions through history, with "which people identify, independently of ownership, as a reflection and expression of their constantly evolving values, beliefs, knowledge and transitions" (p. 2). These policies accentuate the importance of active engagement and citizen participation in decision making processes about space, as well as the knowledge about the origin and the effects of space and its facets. BE should be made a central educational topic, addressed at all levels of education (Art. 13, Council of Europe, 2005: 5-6; Davos Declaration, 2018: 12), as this so far was rarely the case.

The second group of studies reveals that monuments can teach about local cultural heritage in heritage and history (Moreeng, 2014), social studies (Hunter, 1993) and sustainable development (DSD, 2018). The empirical evidence highlights including cultural heritage in the curriculum, as $58 \%$ of teenagers from a study by Bradley et al. (2011) perceived at least one historic building in the local area, as distinctive, and personally significant. Yet, Moreeng (2014) calls for the reconceptualization of the cultural heritage teaching in schools to allow critical approach able to enhance pupils deeper understanding of the heritage. The work of architects and urban planners as educators can hardly be discerned in the existing academic debate. Brković Dodig (2018) mentioned the role of architects when tecahing BEE with historical buildings in a museum context. Plein (2009) explored Denkmalpädagogik (monument pedagogy) projects in German schools where architects and urban planners took part. Heinrich and Million (2016) researched the engagement of young people in neighborhood development projects including the (re-)use of cultural heritage.

Observing the work within the third group of literature consisting of educational guides for teaching/learning with monuments (Fachwerk, n.d.; Schmidt-Breitung and Michels, 2018; DSD, 2018), the role of architects as creators and facilitators of BEE programs with monuments in focus can be seen. However, their contribution to the existing academic debate is scant. Architects and planners seldom find time to critically reflect on their practice as educators; thus, we lack constructive criticism, knowledge exchange and stronger evidence base. This paper ventures into narrowing this identified gap.

\section{Objectives and methodology}

The aim of this paper is: to examine and provide a brief overview of this emerging field through literature review, in order to contextualize the work of architects and urban planners as educators when using cultural heritage as a BEE curricular resource; to explore one illustrative case study to provide critical analysis based on it; and ultimately develop key points interpreted through existing theory and literature, coming from both architecture, pedagogy and education, in order to formulate important points which can hopefully initiate the future discussion.

A qualitative methodology and an inductive approach was adopted, to explore a deeper meaning behind human experiences, and to "document the world from the point of view of the people" participating in the research - from the architects` and planners` working as educators point of view; and in that way provide a "deeper understanding of social phenomena" (Silverman, 2008: 8) - the use of monument as a BEE teaching resource. A case study strategy offered the opportunity to build a rich picture of this phenomenon, in a particular context (Yin, 2008). Case studies are flexible allowing exploration while the research unfolds, they accentuate in-depth context, and lead to creating hypothesis that can be later tested. An illustrative case study of ' $L T$ ' project was adopted as a mean to make the unfamiliar work of architects and urban planners-educators more familiar. Illustrative case studies are useful in describing what the situation is like, in interpreting other data, thus creating a common language between authors and readers coming from different professions (Davey, 1991). A qualitative research technique - focus group discussion was select as it allowed us researchers to: "assembles a group of individuals to discuss a specific topic, aiming to draw from the complex personal experiences, beliefs, perceptions and attitudes of the participants" (Nyumba et al., 2018: 21). Five architects and urban 
planners, including the authors, working as researchers and practitioners in this field held three workshops. In the first one they reviewed available knowledge in the field, and in the second one they in-depth discussed the ' $L T$ ' project. The first two workshops were audio recorded and later transcribed. For analyzing the transcripts, qualitative content analysis as explained by Mayring (2000) was applied. The first and the second author coded the transcripts in search for the categories that kept reappearing. Through a feedback-loop categories were reviewed, and ultimately reduces to the main ones. Afterwards the third workshop was facilitated so that all participants could reach consensus and establish themes able to initiate further discussion. Interpretation of the data was further supported by existing theory and literature from the fields of architecture, pedagogy, and education. This process ultimately led to the development of a key set of messages that might usefully inform the work of architects and urban planners as educators within the BEE field.

\section{Case study}

' $L T$ ' project was selected as an illustrative case study. As this study does not aim to infer from this sample to a general population, non-probability convenience sampling was adopted. It fitted this small, pilot, exploratory study aiming to generate the first hypothesis to be further tested, discussed and refined. 'Lost Traces... eine baukulturelle Spurensuche' (search for traces of cultural heritage) was a part of the 2018 European Year of Cultural Heritage. It was developed by the Landesarbeitsgemeinschaft (LAG) Architektur und Schule Bayern e.V. (regional working group Architecture and School in Bavaria). The project aimed to encourage young people to actively engage with historic relics as traces of European cultural heritage, and through a series of educational and artistic engagements, transform them into the elements of a common European future (the future perspective is probably the greatest difference of how historians and conservators use monuments in education). All the projects stressed examining the cultural heritage in relation to its context. ' $L T$ ' used historical relics in the landscape, hidden archaeological traces, urban wastelands, abandoned buildings and constructions which reveal European cultural heritage. These places over time have: 'fallen into oblivion' and their 'demolition, conversion or development is currently publicly discussed' (LT, n.d.: 6). Locally significant buildings that still do not have the official monument status were included. ' $L T$ ' comprised of 23 individual projects, mainly carried out in secondary and high schools (age 10-18) in Bavaria and implemented through a cooperation with local partners. Teachers worked with professionals from monument conservation, archaeology, urban development, architecture, and creative industries in order to connect teaching with monuments and cultural heritage themes. The projects took place during 2017/18 and 2018/19 academic year, lasting from a few days to a whole school year. The authors participated in several project workshops, which enabled them to have a closer look at how teaching with monuments was organized within the project.

' $L T$ ' projects were based on self-directed and practice-oriented learning. Each project began with the site exploration - photo and video documentation were made, books were researched and locals interviewed so that the places could be personally and collectively experienced. Drawings, photography, collages, maps, and 3D models assisted pupils to deepen their thinking about the place, as well as to showcase individual and group sentiments and ideas. Afterwards pupils researched the archives, analyzed the maps, and develop their own question in order to understand the potential of the place as a cultural heritage site. The last phase tasked pupils to find new spatial qualities, thus new functions and usages for the sites. Pupils ideas and suggestions were developed through creative spatial interventions, artistic scenography, street art, light installations, guided tours, exhibitions, concerts or communal meals. In this way pupils actively engaged with the site, its history and its potential, rediscovered it, draw public awareness, stimulated discussion, tested new uses, and provided ideas for future development.

\section{Discussion}

Through the group discussion the experts reached consensus around four following themes that should serve as an invitation, trigger and stimuli for further debate.

$\mathrm{BE}$ features as curricular resource should be perceived as a constantly evolving cultural construct. Architects and urban planners' understanding of space, thus of monuments as learning objects, is informed by the works in sociology and architecture that challenge conventional understanding of space. In particular they are informed by Lefebvre`s work stating that space is produced through social action, and should be seen as a dynamic construct, consisting of physical location, actors and activities, which are continually transforming each other. The educational practice of architects and urban planners goes in line with the criticism coming from education and cultural heritage studies. Cultural heritage should not be perceived as a collection of factual data, and should not only be read through the standardized notion that history is a sum of information about the past without being contextualized in the present (Moreeng, 2014). Pupils should have an opportunity to (re-) negotiate "the representation of a 
collective memory through the creation of their own monument" (Uhrmacher and Tinkler, 2007: 11). The accent should be put on cultural heritage interpretation. In the 'LT' project called Raumlabor Spitalkirche different generations - pupils, teachers, parents, grandparents and other residents, explored history of the local church through personal family stories and negotiated interim future uses. While one group at the end built a huge chandelier as an architectural installation, the other shot a VR film to explore their church vision virtually. Understanding that space is not a fixed construct architects and urban planners as educators invited pupils to enter a personal, critical and creative dialectic relationship, embrace the visions of others, in order to explore current monument and transform them into 'their own'.

The knowledge as well as the space is constantly evolving cultural construct. Therefore, architects as educators put stronger accent on the quality and richness of the educational experience. The learning was not result, goal and assessment oriented. The ultimate task was not a production of a piece of work (essay, photos, presentations etc.) that could be later marked; as it is often the case in schools. Instead, the accent was on iterative learning cycles, where one stage manifested in the form of an essay, a photo or a presentation could inform and initiate the next one, thus forming an educational continuum. The goal was to convey to others a tangible sense of individual learning experience of the topic learned. In order to explore and analyses 'lost traces' in different ways pupils combined inspiration collages, plan analysis, with photo documentation and search in archives. Gathered historical information was paired with personal impressions of a monument. The pedagogical value of such educational experience is in the performative relationship between the pupil and the monument. Teaching with spatial features defines pedagogy not as a "curricular craft whose goal is the transfer of knowledge, but rather as the production of conditions that make movement to and from bodies of knowledge possible" (Lee, 2008: 194). Ellsworth (2005) argues that space as pedagogies are about putting into relation the inside (inner thoughts, memories, ways of knowing and being, fears, and desires) and the outside (others, events, history, culture, and socially constructed ideas). In her words: "Architecture becomes pedagogical, pedagogy becomes architectural when they create fluid, moving pivot place that puts inside and outside, self and other, personal and social into ... a mutually transforming relationship" (p. 38, 41) (Ellsworth, 2005).

Architects and urban planners as educators work as 'the educative planners'; they take the role of "a facilitator of personal empowerment and social transformation, and foster social learning and participation" (Million and Parnell, 2017:78). Their work is informed by Vygotsky's (1978) 'Zone of Proximal Development Theory' as they assume that children co-construct knowledge with more experienced adults; as well as by the concept of transformative pedagogy by (Giroux, 2011) suggesting that teaching is an emancipatory reciprocal process impacted by political, ethical and moral realm. As one of the ' $L T$ ' projects shows a central concern of the educative planners working with pupils was on making cultural heritage experience available for the public. In the 'Regensburg Anatomy Tower' project they decided to present the results in a form of a guided tour of the tower, offered at a local festival, thus transforming the tour into a dialectic educational experience, where pupils could benefit from the knowledge and perspective of the visitors, and vice versa. The quality of such learning process is in stimulating the pupils to act as curators of their own educational experience while working alongside architects, urban planners, teachers, restaurateurs, conservators and craftsman as advisors and partners.

Architects and urban planners appropriate design tools, learned at university and used later in practice, and transform them into BEE tools. In ' $L T$ ' project mapping, photography, scratching, painting, drawing, dance and performance, were combined to enable engagement with the learning materials according to each pupil's personal predispositions and learning style. These tools stimulate personal and often sensory engagement with the learning materials, making the feelings and the impressions an inextricable part of the learning process. The learning process aided with these tools reassembles the architectural design and planning process, where numerous iterative phases must be carried out, with the help of several tools, so that one object is designed.

\section{Conclusions}

The success of the BEE project as learning experiences with monuments in focus can be attributed to several factors. When using cultural heritage as curricular resource for children, architects and urban planners as educators, challenge the standardizes and general perceptions of a monument and its meaning through a learning processes designed to be personally relevant, self-directed, with self-initiated topics; allowing a multitude of learning styles, personal interest, individual capabilities and creative impulses to be enacted through the educational experience. They ventured into creating a longer lasting 'relationship' with the monument, thus longer lasting educational effect, that stays vivid in children's memory as it was personally relevant and personally experienced. Such educational processes can potentially transform pupils into the cognizant future citizens, able to identify locally important BE issues, and take knowledgeable action towards them; value the importance of local heritage and initiate their preservation - important aspects advocated by both Davos Declaration and Faro Convention.

The goal of this paper was not to make any great claims and provide conclusive answer, but instead to start a reflection on educational practice of architects and urban planners when using cultural 
heritage as curricular resource. If we argue that space as educational object, as well as the knowledge, is a constantly evolving cultural construct what practical consequent for teaching does that has? Also, what theories are framing and informing our work? So that the larger number of children can benefit from such educational programs who is the most appropriate facilitator - schools that cater to the needs of the widest children population, but are assessment, goal and final product driven; or museums and children`s clubs who can facilitate such open ended educational experience, but are usually costly? How can we advance our teaching practice without critically reflecting on our work as educators? How do we modify and appropriate design tools to be successful educational tools? The ability of the educative planners to foster good quality educational experiences in the future, using monuments and other facets of our BE as curricular resource, will heavily depend on our ability to answer previously posed questions, open up the debate, and exchange knowledge with educators, pedagogies, psychologists and other relevant professions, so as to critically reflect on our successes as well as failures.

\section{References}

Bradley, D., Coombes, M., Bradley, J. \& Tranos, E. (2011). Assessing the importance and value of historic buildings to young people. London: English Heritage.

Brković Dodig, M. (2018). Built environment education for children: Museums in focus. Urban Design and Planning 171(1), 13-24.

Davey, L. (1991). The Application of Case Study Evaluations. Practical Assessment, Research \& Evaluation, 2 (9). Retrieved May 9, 2019, from: http://PAREonline.net/getvn.asp?v=2\&n=9.

Davos Declaration (2018). Bern: Federal Office of Culture, Cultural Heritage and Historic Monuments Section.

Deutsche Stiftung Denkmalschutz (2018). Lernen am Denkmal. Retrieved May 8, 2019, from: https://denkmal-aktiv.de/materialien/arbeitsblaetter/

Ellsworth, E. (2005). Places of learning: Media, Architecture, Pedagogy. New York: Routledge.

Fachwerk (n.d.) Baukultur aktiv. Baudenkmäler im Unterricht praxisorientiert erleben. Retrieved May 8, 2019, from: https://www.fachwerk.erz.be.ch/schule/

Council of Europe (2005). Faro Convention on the Value of Cultural Heritage for Society. Retrieved May 8, 2019, from: https://www.coe.int/en/web/culture-and-heritage/faro-convention

Giroux, H. A. (2011). On Critical Pedagogy. New York: Continuum.

Graves, G. (1990). Teaching about the Built Environment. ERIC Digest. Retrieved May 7, 2019, from https://www.ericdigests.org/pre-9217/built.htm

Heinrich, A. J. \& Million, Angela (2016). Young People as City Builders. Youth Participation in German Municipalities. dis-The Planning Review 204 (52.1), 56-71.

Hunter, K. (1993). Teaching with Historic Places. ERIC Digest. Retrieved May 7, 2019, from: https://www.ericdigests.org/1994/places.htm

LOST Traces (n.d.). Landesarbeitsgemeinschaft (LAG) Architekur und Schule Bayern e.V. Retrieved May 8, 2019, from: http://lost-traces.eu/idee/

Lee, M. (2008). Curating the Pedagogical Scene. Pedagogy 8 (1), 194-198.

Mayring, P. (2000). Qualitative Inhaltsanalyse [28 Absätze]. Qualitative Social Research, 1 (2), Art. 20, Retrieved May 10, 2019, from: http://nbn-resolving.de/urn:nbn:de:0114-fqs0002204.

Million, A. and Parnell, R. (2017). The Educative Planner. dis-The Planning Review, 53(2), 78-79.

Nyumba, T., Wilson, K., Derrick, C. and Mukherjee, N. (2018). The use of focus group discussion methodology: Insights from two decades of application in conservation. Methods in Ecology and Evolution 9 (9), 20-32.

National Park Services (2016) Teaching with historic places. Retrieved May 7, 2019, from: https://www.nps.gov/subjects/teachingwithhistoricplaces/lesson-plans.htm

Moreeng, B. B. (2014). Reconceptualising the teaching of heritage in schools. SAJHE 28 (3A), 767-786.

Plein, I. (2009) Denkmalpflege Pädagogik in Baden-Württemberg. Denkmalpflege in Baden-Württemberg 38 (4), 208-216.

Schmidt-Breitung, D. \& Michels, I. (2018). Lernen am Denkmal - Gute Gründe für den Lernort und Tipps für den Unterricht. Bonn: Deutsche Stiftung Denkmalschutz.

Silverman, D. (2008). Doing Qualitative Research: A comprehensive guide. London: SAGE.

Uhrmacher, B. \& Tinkler, B. (2007). Engaging learners and the community through the study of monuments. International Journal of Leadership in Education 11 (3), 225-238.

Vygotsky, L. (1978). Mind in Society: The development of higher psychological processes. Cambridge, MA: Harvard University Press.

Yin, R. K. (2008). Applications of Case Study Research. Los Angeles/London: SAGE. 